\title{
LEADERSHIP IN TIMES OF CRISIS: A FRAMEWORK FOR ASSESSMENT*
}

\author{
ARJEN BOIN \\ Utrecht University, Netherlands \\ SANNEKE KUIPERS \\ Utrecht University, Netherlands \\ \& \\ WERNER OVERDIJK \\ Crisisplan, Netherlands
}

\begin{abstract}
The deeply rooted belief in the importance of public leadership is accompanied by quick and often shallow assessments of leadership performance. Such assessments never arrive more quickly than in the wake of crises and disasters - these episodes make for instant winners (Giuliani) and losers (Bush). These assessments are necessarily shallow, as the public can only judge leaders by what they see. While symbolic performance is important (if only because it can arouse the public), it is not the only performance dimension by which we should assess crisis leadership. In this article, we reflect on the many tasks that strategic leaders are called to perform, and we offer a comprehensive framework for leadership performance in times of crisis.
\end{abstract}

Key Words: crisis management, executive tasks, crisis leadership, assessment

\section{INTRODUCTION: THE PERENNIAL CALL FOR LEADERSHIP}

The events of September 11, 2001, provided two American leaders with an opportunity to redeem themselves by demonstrating their leadership qualities. The mayor of New York City, Rudy Giuliani, had reached the end of his term and was poised to go 
down in history as a political failure. The U.S. president, George W. Bush, had experienced a rocky start in his presidency after a photo-finish victory and was facing declining poll numbers. Both men emerged from this deep crisis as leaders. They enjoyed respect and wide popularity, even if it was not clear what, exactly, they had done to deserve this upward reputational swing.

The Hurricane Katrina disaster, in the summer of 2005, produced losers rather than winners. The governor of Louisiana, Kathleen Blanco, chose not to run again (she was sure to lose). The director of the Federal Emergency Management Agency, Michael Brown, was fired weeks into the disaster. The Secretary of Homeland Security, Michael Chertoff, had to face a barrage of criticism. Most of the criticism, however, was aimed at President Bush, who had to defend himself against accusations of being disengaged and non-interested in the fate of the Black population still in New Orleans. Winners included the mayor of New Orleans (Ray Nagin), Coast Guard Commander Thad Allen, and General Russell Honoré, who became a folk hero in his native Louisiana.

Academics have extensively studied how politicians and the public at large arrive at these collective assessments (Bovens and 't Hart, 1996). They are the outcome of a messy process that is infused by the "dynamics of accountability" (Brandström and Kuipers, 2003; Boin, McConnell and "t Hart, 2008; Hood, 2011). The search for explanations- how could this have happened?-often degenerates into "blame games." Media appoint winners and declare losers. Political inquiries tend to be preoccupied with the unearthing of failures, especially those that might explain why the crisis was not prevented in the first place. When a final verdict emerges, it tends to come in the form of a "winning narrative" that features heroes and culprits.

This rush to judgment presumes that crisis leadership matters. But the academic evidence that leadership is important during crises and disasters is impressionistic at best. We know how crisis leaders can make a crisis worse: by ignoring impending threats, by making "stupid" decisions, or by acting in ways that suggest they do not care (Boin and 't Hart, 2010). Every case study produces examples of (in)actions that - in hindsightcan be argued to have had a negative effect on the outcome. Yet, a focus on individual omissions does not add up to a theory of crisis leadership that explains what crisis managers can do (or should not do) to minimize the impact of a crisis or disaster.

When verdicts on crisis leadership are based on a combination of partial assessment and blame game performance, citizens are not presented with an informed assessment of a society's crisis management capacities. Mayor Giuliani and the New York City police officers and firefighters may have become heroes, but that does not tell us anything about their crisis management performance. The population of New Orleans suffered tremendously in the wake of Hurricane Katrina, but that does not automatically mean that all people and organizations involved in the response must have failed.

These incidents prompt a set of questions. How can we assess leadership performance during a crisis or disaster (cf. 't Hart, 2011)? What can we reasonably expect from 
leaders at the strategic or political level? How important is their role as crisis manager? In this article, we seek to provide a preliminary framework for assessing leadership performance by identifying the critical functions of crisis management and formulating criteria for assessing their performance.

\section{What Can We Reasonably Expect from Crisis Leaders?}

We define crisis management as the sum of activities aimed at minimizing the impact of a crisis. Impact is measured in terms of damage to people, critical infrastructure, and public institutions. Effective crisis management saves lives, protects infrastructure, and restores trust in public institutions.

Negative outcomes are often related directly to ineffective crisis management. Recent "mega crises" such as Hurricane Katrina, the BP oil spill, the financial crisis, and the nuclear disaster in Fukushima have been followed by scathing assessments of crisis management performance (ranging from "failures of imagination" to "failures of initiative").

There are many reasons that we should not expect too much from crisis management. Consider how many factors affect the outcome of a crisis or disaster: the size, speed of onset, and "knowability" or predictability of a threat agent determine how much leeway there is for crisis performance. In addition, the effects of the response are affected by the behavior of other actors, such as NGOs, media, competitors, victims, and bystanders. Finally, the outcome is informed by the available resources that will help a stricken society recover.

At the same time, there is plenty of evidence to suggest that crisis management matters. We assume crisis management can make an impact, however modest, on the outcome of a crisis. The effectiveness of crisis management can be assessed along the following dimensions:

- Making things happen: crisis management is about organizing, directing, and implementing actions that minimize the impact of a threat;

- Getting the job done: forging cooperation between previously unrelated agents; and enabling "work arounds" when routines and resources do not work;

- Fulfilling a symbolic need for direction and guidance.

The formulation of these dimensions is, of course, a normative exercise. But it helps us think through how crisis management activities contribute to these aims. It helps us connect process and outcome, while taking the difficulty of a particular crisis into account. The key question is: Did those charged with crisis management responsibilities do everything they could to facilitate an effective response to the crisis at hand?

Before this question can be answered, we need to further "unpack" the set of tasks that make up crisis management. We identify what may be called the "executive tasks of crisis management" (cf. Barnard, 1938) and consider how these tasks are best fulfilled. 


\section{EXECUTIVE TASKS OF CRISIS MANAGEMENT}

Imagine you are a member of an inquiry committee that is charged with the evaluation of how a public organization handled a certain crisis. You know that the outcome of the crisis - whether it is widely considered an unprecedented disaster or a miraculous "near miss"-is irrelevant. The committee should concentrate on how well the most important tasks of crisis management were executed. The committee is given, as guidelines for its evaluation, ten executive crisis tasks that were culled from extensive studies of crisis management in a variety of settings (Rosenthal, Charles and 't Hart, 1989; Quarantelli, 1997; Rosenthal, Boin and Comfort, 2001; Boin et al., 2005; Donahue and Tuohy, 2006; Boin and 't Hart, 2010).

\section{Task \#1: Early Recognition}

Effective crisis management begins with a shared recognition that a threat has emerged which requires immediate attention. If one were to read a randomly selected set of inquiry reports, one would take away the impression that most crises could have been foreseen. That is not a realistic (or fair) assessment. In hindsight, when the outcome is clear, it often seems that a crisis was foreseeable (Turner, 1978; Tetlock, 2005; Woods, 2005; Comfort, 2007). But what realistically could have been foreseen in the early stages of a crisis, when signals were only bits of fragmented information?

Two factors identified in previous research may spur "foresight" (cf. Turner, 1978). The first factor is extensive experience with crisis and its dynamics. Some operators have developed an ability to recognize deviations from complex but known processes (Roe and Schulman, 2008). Experienced firefighters, for instance, can develop a keen sense of impending danger. The second factor is organizational: some organizations have a culture in place that facilitates rapid collective awareness of impending threats (Weick and Sutcliffe, 2002). The common denominator appears to be continuous vigilance, a shared awareness that something can happen at any given moment, and a willingness to act on faint signals, plus a tolerance for false alarms or voluntary admissions of error.

What to look for: Did leaders create conditions that facilitate early recognition?

\section{Task \#2: Sensemaking}

During a crisis, it is a real challenge to arrive at a collective understanding of the nature, characteristics, consequences, and potential scope and effects of an evolving threat. This sensemaking task is crucial if crisis managers are to make informed decisions. There is an extensive literature explaining why most people find it very hard to process and share information under conditions of stress and deep uncertainty (Reason, 1990; Kahneman, 2011; Coates, 2012). 
Effective sensemaking requires a well-rehearsed method to process information, share it with the right people and consider their feedback, create a dynamic picture that everybody understands, analyze possible "futures" and potential consequences, and formulate specific information needs (which somehow must be met). Some organizations (think of NASA or the worldwide network of government-sponsored computer emergency response teams [CERTs]) have extensive sensemaking machinery in place, but that is - as we know - not a guarantee that a shared picture of the situation will emerge in time. Louise Comfort and Aya Okada (2013) outline the intriguing idea of creating a "knowledge commons" to support crisis leaders in extreme events.

What to look for: Did leaders create, facilitate, and rehearse a sensemaking method?

\section{Task \#3: Making Critical Decisions}

Crisis management has often been analyzed in terms of decision making. At the strategic level, making critical decisions - those that should be made at the highest level —is indeed an important, sometimes crucial, task. There is widespread agreement among researchers that strategic crisis managers should only concern themselves with strategic issues; they must avoid becoming entangled in operational decision making (Boin et al., 2005). Effective crisis leaders orchestrate a process of adaptation, not a search for technical fixes (Heifetz, 1994). They are not "answer-giver in chief" (Leonard and Howitt, 2012: 51). This is harder than it looks, for strategic decisions do not come with labels indicating whether they are best made at the strategic or operational level. As strategic issues tend to be few and operational issues tend to be many, there is a clear temptation to become engaged with the operational level. This is known as "micro management," and it usually meets with little appreciation on the shop floor.

But what makes a good decision? Academics who wish to apply an objective focus will likely emphasize the importance of sound process (George, 1980). Another approach would be to assess if and how critical decisions reaffirm and (re)define core institutional or societal values (Leonard and Howitt, 2009). Legalists would emphasize whether managers played by the rules, and whether they applied principles of subsidiarity and proportionality.

What to look for: Did leaders carefully deliberate which decisions they should make, and did they make the decision after some form of due process?

\section{Task \#4: Orchestrating Vertical and Horizontal Coordination}

A crisis or disaster typically requires intense cooperation among a variety of organizations, many of which may have never worked together before (Boin and 't Hart, 2012). Such cooperation across vertical and horizontal borders must be orchestrated to accomplish a state of coordinated behavior. The activity of "orchestrating" behavior lies 
somewhere on a continuum between the extremes of persuasion and "command and control." Persuasion is not enough to bring all parties to a state of optimal cooperation. Command and control, on the other hand, tends to backfire.

Disaster researchers point to the capacity of self-organization: affected communities, local organizations, and victimized citizens can be surprisingly adaptive, creating nodes of cooperation that are well suited to the situation at hand (Carr, 1932; Drabek, 1985; Comfort and Okada, 2013). If self-organization appears to be effective, central authorities should hold back. In those situations, effective leaders are "asking more than telling, requesting rather than ordering, delegating and decentralizing rather than narrowing and centralizing" (Quarantelli, 1988: 382). Sibout Nooteboom and Katrien Termeer (2013) refer to "enabling leadership." If, however, network parties refuse to cooperate, the officials in charge should intervene and remove boundaries to cooperation.

What to look for: Did crisis leaders monitor and assess forms of vertical and horizontal cooperation? Did they facilitate effective cooperation and intervene where cooperation was lacking or dysfunctional?

\section{Task \#5: Coupling and Decoupling}

Charles Perrow (1984) famously described how seemingly small incidents can spiral out of control in complex and tightly linked systems. Escalation poses the challenge of "decoupling": system managers must try to "island" the problem—allowing the system to "fail gracefully"-while protecting as many core functions as possible. Cyber threats and the volcanic ash crisis (2010) provide examples of crises where decoupling became necessary.

The opposite also happens. Sometimes critical systems become detached from their life lines as a result of some type of shock. After Hurricane Katrina, for instance, many critical systems in the city of New Orleans needed to be "switched back on"- an equally daunting task for crisis managers. At the strategic level, crisis managers must figure out which systems should be switched off and which ones should be put on life support. This not only requires an intimate knowledge of complex systems, but also capacities for transboundary cooperation (Ansell, Boin and Keller, 2010).

What to look for: Did crisis leaders actively monitor the state of critical (lifesustaining) systems and the connections between them? Did they access expertise with regard to these critical systems?

\section{Task \#6: Meaning Making}

When a society is hit by a crisis, members of that society will look to their leaders to hear how they interpret the situation and what they plan to do to restore a state of normalcy. Leaders are expected to provide "authentic hope and confidence" (Leonard 
and Howitt, 2009). If they present a convincing story, they will impose a dominant "frame" through which events are viewed and interpreted. A good story helps to construe "beliefs about the significance of events, of problems, of crises, of policy changes, and of leaders" (Edelman, 1985: 10). If incumbent leaders are not successful in imposing such a frame, their opponents will try to impose their frame, which may give rise to interpretations that are less supportive of the ongoing crisis management efforts.

The process of meaning making, in other words, is crucial to the (long-term) legitimacy of public institutions (cf. Rosenthal, Boin and Bos, 2001). An effective story relates the events to the core values of an organization or a society. It explains how crisis management efforts will help to confirm or adapt these core values.

What to look for: Did crisis leaders offer a clear interpretation of the crisis and explain how they intended to lead their community out of it?

\section{Task \#7: Communication}

During a crisis, communication with citizens and between organizations is incredibly important. It is also one of the main sources of problems, as means of communication often break down or become overloaded in the midst of a crisis. Botched communications can have severe repercussions for the safety of people and for how a crisis management operation is perceived.

There is an abundance of research explaining how mass communication in crises is best done (Drabek, 2001; Fearn-Banks, 2007). It should explain the crisis, its consequences, and what is being done to minimize the consequences. It should also offer "actionable advice," explaining what should be done, by whom, and why.

There is a clear difference between the strategies and skills of "routine" communications and crisis communication (Goidel and Miller, 2009). Standard repertoires may not work in a crisis. For instance, what works to sell policy or a candidate does not necessarily work in a crisis. The context of a crisis is too different: it is marked by a much faster and unpredictable pace and persistent difficulties in verifying information. Communication techniques need to be adapted for crisis situations.

What to look for: Did crisis leaders actively cooperate with their communications professionals to ensure they had timely and correct information for dissemination to the public?

\section{Task \#8: Rendering Accountability}

A crisis is a critical episode for a society. The outcome may have long-lasting effects on the future well-being of that society and its members. Crisis managers therefore have a responsibility to explain what was done before and during the crisis, and why. They should explain what worked and what went wrong during a crisis. Rendering 
accountability does not only satisfy legal and moral requirements, it also allows for the restoration of trust in the functioning of public institutions.

In practice, crisis managers find it very hard to perform this task. Public officials quickly become defensive: they are less concerned with claiming credit than with avoiding blame (Weaver, 1986), and understandably so. All too often, the "blame game" begins before the operational or "hot" phase of the crisis has come to an end. The prospect of a political inquiry, a regular element of the contemporary crisis aftermath, strengthens the defensive posture of crisis managers. Accountability, in short, is affected by the inherent politicization of a crisis.

What to look for: Did leaders make an effort to present a transparent and constructive account of their (in)actions before and during the crisis?

\section{Task \#9: Learning}

As every crisis is unique, crisis management requires, by definition, the capacity to improvise, discover, and experiment. It is therefore important that crisis managers have the capacity to learn (Comfort, 1999). This capacity is important both during a crisis (what works?) and after a crisis (what worked?). Learning is a prerequisite for adaptation, which, in turn, should help to correct dysfunctional processes and facilitate freshly discovered solutions. Learning, both during and after a crisis, is an incredibly complex process (Stern, 1997). It has high symbolic value: organizations had better demonstrate that they seek to learn from failure. The official vehicles for learning, inquiry committees and investigation boards, have to do their work in highly charged political environments that are infused by blame-game dynamics (Sulitzeanu-Kenan, 2010).

Effective learning resembles the maxims of scientific research: it continuously tests hypotheses against reality. It takes into account different factors at different levels, such as human error, organizational culture, regulation, and system characteristics. These are weighted against the possibility of bad luck or randomness. Effective learning takes time, requires a special culture of inquiry, and may not lead to clear-cut results or politically desirable outcomes.

What to look for: Did leaders allow for reflection on the effects of chosen courses of action, did they encourage and tolerate negative feedback, and did they record crisis management proceedings to facilitate learning by outsiders?

\section{Task \#10: Enhancing Resilience}

Few would disagree with the notion that a prepared organization or network is likely to be more effective in the management of a crisis. It is impossible to prepare in detail for every crisis or disaster that may occur (Clarke, 1999). It is therefore crucial that 
organizations possess a degree of flexibility and a capacity to rapidly adapt in the face of negative feedback. Effective crisis management is served by resilient organizations, which can absorb blows and recover quickly. The problem is that we do not know how to create such resilient organizations (Comfort, Boin and Demchak, 2010).

One of the key factors in building well-prepared, resilient organizations is to engage constantly in preparatory practices, such as vulnerability analyses, drills, scenario exploration, and network exercises. These activities create a culture of awareness, a sense that things may go wrong, but also a shared belief that all involved stand ready to cope with whatever threat they may face (Weick and Sutcliffe, 2002). Resilience can thus be viewed as a result of hard work and elite involvement.

What to look for: Did leaders actively involve themselves in crisis preparations?

\section{CONCLUSION: TAKING CRISIS MANAGEMENT SERIOUSLY}

A common refrain in academic studies of crisis management holds that crises pose ever more difficult challenges that traditional bureaucracies find increasingly hard to meet (Light, 2008; Lagadec, 2009). There is undoubtedly a kernel of truth to this observation. The consequences of natural disasters are becoming more serious by the year. Modern crises are becoming in important ways transboundary in nature, creating challenges across geographic and policy borders (Ansell, Boin and Keller, 2010; OECD, 2011). It is also true that bureaucratic governance structures, processes, staffs, and "cultures" are not designed to cope successfully with radically novel situations, predicaments, and opportunities.

Societies need a common understanding of what crisis leaders should do to enhance crisis management effectiveness. In the absence of such an understanding, crisis leaders are subjected to a messy process of collective framing, from which they can just as easily emerge a winner or a loser. Given the increasing importance attached to crisis management, an evaluation of leadership driven by politicization and media dynamics is simply unacceptable.

In this article, we set out to formulate an evaluative framework that can be used to assess leadership performance before, during, and after a crisis. The framework trains the attention of evaluators on all the crisis tasks that leaders are asked to perform (not just those tasks that are performed in the media spotlight). By taking a comprehensive view of crisis leadership, the resulting assessment is more likely to be fair and to take into account the difficult conditions under which crisis leaders operate. 


\section{NOTE}

* The authors would like to thank Louise Comfort and Sandra Resodihardjo for their detailed comments and suggestions.

\section{REFERENCES}

Ansell, Chris, Arjen Boin and Ann Keller. 2010. Managing Transboundary Crises: Identifying Building Blocks of an Effective Response System. Journal of Contingencies and Crisis Management 18 (4): 205-217.

Barnard, Chester I. 1938. The Functions of the Executive. Cambridge, MA: Harvard University Press

Boin, Arjen and Paul 't Hart. 2012. Aligning Executive Action in Times of Adversity: The Politics of Crisis Coordination. In Executive Politics in Times of Crisis, edited by Martin Lodge and Kai Wegrich. Houndmills: Palgrave (179-196).

. 2010. Organising for Effective Emergency Management: Lessons From Research. Australian Journal of Public Administration 69 (4): 357-371

Boin, Arjen, Allan McConnell, and Paul 't Hart. eds. 2008. Governing After Crisis: The Politics of Investigation, Accountability and Learning. Cambridge: Cambridge University Press.

Boin, Arjen, Paul 't Hart, Eric Stern, and Bengt Sundelius. 2005. The Politics of Crisis Management: Public Leadership Under Pressure. New York: Cambridge University Press.

Bovens, Mark and Paul 't Hart. 1996. Understanding Policy Fiascoes. New Brunswick: Transaction.

Brändström, Annika and Sanneke Kuipers. 2003. From "Normal Incidents" to Political Crises: Understanding the Selective Politicization of Policy Failures. Government and Opposition 38 (3): 279-305.

Carr, Lowell. 1932. Disaster and the Sequence-Pattern Concept of Social Change. American Journal of Sociology 38:207-218.

Clarke, Lee. 1999. Mission Improbable. Chicago: The University of Chicago Press.

Coates, John. 2012. The Hour Between Dog and Wolf: Risk-taking, Gut Feelings and the Biology of Boom and Bust. London: Fourth Estate.

Comfort, Louise K. 1999. Shared Risk: Complex Systems in Seismic Response. New 
York: Pergamon Press.

2007. Crisis Management in Hindsight: Cognition, Communication, Coordination, and Control. Public Administration Review 67 (Special Issue): S188-S196.

Comfort, Louise K., Arjen Boin, and Chris Demchak. (Eds.) 2010. Designing Resilience for Extreme Events. Pittsburgh: Pittsburgh University Press.

Comfort, Louise K. and Aya Okada. 2013 Emergent Leadership in Extreme Events: A Knowledge Commons for Sustainable Communities. International Review of Public Administration 18 (1): 61-77.

Donahue, Amy K. and Robert Tuohy. 2006. Lessons We Don't Learn: A Study of the Lessons of Disasters, Why We Repeat Them, and How We Can Learn from Them. Homeland Security Affairs 2 (2).

Drabek, Thomas E. 2001. Disaster Warning and Evacuation Responses by Private Business Employees. Disasters 25 (1): 76-94.

Edelman, Murray. 1985. The Symbolic Uses of Politics. Urbana: University of Illinois Press, 1985

Fearn-Banks, Kathleen. 2007. Crisis Communications: A Case Book Approach. Mahwaw, NJ: Lawrence

George, Alexander L. 1980. Presidential Decisionmaking in Foreign Policy. Boulder, CO: Westview Press.

Goidel, Robert and Andrea Miller. 2009. News Organizations and Information During a Natural Disaster: Lessons from Hurricane Katrina. Journal of Contingencies and Crisis Management 17 (4): 266-273.

Heifetz, Ronald A. 1994. Leadership Without Easy Answers. Cambridge: Harvard University Press.

Hood, Christopher. 2011. The Blame Game. Princeton: Princeton University Press.

Kahneman, Daniel. 2011. Thinking, Fast and Slow. London: Allen Lane.

Klein, Gary. 2009. Streetlights and Shadows: Searching for the Keys to Adaptive Decision Making. Cambridge: The MIT Press.

Lagadec, Patrick. 2009. A New Cosmology of Risks and Crises: Time for a Radical Shift in Paradigm and Practice. Review of Policy Research 26 (4): 475-488.

Leonard, Herman B. and Arnold Howitt. 2009. Managing Crises Responses To LargeScale Emergencies. Washington, DC: CQ Press. 
2012. Working Together in Crisis. Crisis Response 7(4): 50-51.

Light, Paul C. 2008. Predicting Organizational Crisis Readiness. New York University: Project on Organizational and Community Preparedness.

Nooteboom, Sibout G. and Catrien J.A.M. Termeer. 2013 Strategies of Complexity Leadership in Governance Systems. International Review of Public Administration 18 (1): $25-40$.

OECD. 2011. Future Global Shocks: Improving Risk Governance. Paris: OECD.

Perrow, Charles 1984. Normal Accidents: Living With High Risk Technologies. Princeton, NJ: Princeton University Press.

Quarantelli, Henry. (Ed.) 1998. What is a Disaster? Perspectives on the Question. London: Routledge.

. 1997. Ten Criteria for Evaluating the Management of Community Disasters. Disasters 21: 39-56.

Reason, James. 1990. Human Error. Cambridge: Cambridge University Press.

Roe, Emery and Paul Schulman. 2008. High Reliability Management: Operating on the Edge. Stanford, CA: Stanford University Press.

Rosenthal, Uriel, Michael Charles and Paul 't Hart. (Eds.) 1989. Coping with Crisis: The Management of Disasters, Riots and Terrorism. Springfield, IL: Charles C. Thomas.

Rosenthal, Uriel, Arjen Boin and Celesta Bos. 2001. Shifting Images: The Reconstructive Mode of the Bijlmer Plane Crash. In From Crises to Contingencies: A Global Perspective, edited by Uriel Rosenthal, Arjen Boin, and Louise Comfort. Springfield: Charles C. Thomas (pp. 200-215).

Rosenthal, Uriel, Arjen Boin, and Louise Comfort. (Eds.) 2001. Managing Crises: Threats, Dilemmas, Opportunities. Springfield, IL: Charles C. Thomas.

Stern. Eric. 1997. Crisis and Learning: A Conceptual Balance Sheet. Journal of Contingencies and Crisis Management 5(2):70.

Sulitzeanu-Kenan, Raanan. 2010. Reflection in the Shadow of Blame: When do Politicians Appoint Commissions of Inquiry? British Journal of Political Science 40: 613-634.

Tetlock, Philip. 2005. Expert Political Judgment: How Good is It? How Can We Know? Princeton, N.J.: Princeton University Press.

't Hart, Paul. 2011. Evaluating Public Leadership: Towards an Assessment Framework. Public Money and Management 31(5): 323-330. 
Turner, Barry A. 1978. Man-made Disasters. London: Wykeham.

Weaver, R. Kent. 1986. The Politics of Blame Avoidance. Journal of Public Policy 6: 371-398.

Weick, Karl and Kathleen Sutcliffe. 2002. Managing the Unexpected. San Francisco: Jossey-Bass.

Woods, David D. 2005. Creating Foresight: Lessons for Enhancing Resilience from Columbia. In Organization at the Limit: Lessons from the Columbia Disaster, edited by William H. Starbuck and Moshe Farjoun. Oxford: Blackwell Publishing (289-308).

Arjen Boin is a professor of Governance and Crisis Management at the Utrecht University School of Governance. He is also an adjunct professor at the Public Administration Institute, Louisiana State University. Email: a.boin@uu.nl

Sanneke Kuipers is attached to the Utrecht University School of Governance and is a senior consultant at Crisisplan BV. Email: s.l.kuipers@uu.nl

Werner Overdijk is the director of Crisisplan BV. Email: Overdijk@ crisisplan.nl

Received: February 26, 2013

Accepted: April 10, 2013 